\title{
Definition of Concept in the Russian Linguistic Field as a Cognitive Category
}

\author{
Dilaram Madaminova', Aida Zulpukarova', Zamira Sabiralieva ${ }^{2}$, Aigul Abdraeva ${ }^{3}$, \\ Kapar Zulpukarov', Darika Bekkulova4, Gulzada Raiymova ${ }^{5}$, Zhypargul Osmonbaeva ${ }^{6}$, \\ Satina Ibraimova ${ }^{4}$, Zhypargul Abdullaeva ${ }^{7 *}$ (1)
}

\author{
${ }^{1}$ Department of Philology, Regional Studies, Mathematics and Computer Sciences, Osh State University, Osh, Kyrgyzstan \\ ${ }^{2}$ Department of Russian Language Teaching Methodic, Osh State University, Osh, Kyrgyzstan \\ ${ }^{3}$ Department of Foreign Languages, Osh State University, Osh, Kyrgyzstan \\ ${ }^{4}$ Department of American Studies and Translation, Osh State University, Osh, Kyrgyzstan \\ ${ }^{5}$ Department of Russian Language Practical Course, Osh State University, Osh, Kyrgyzstan \\ ${ }^{6}$ Department of English Language Teaching Methodic, Osh State University, Osh, Kyrgyzstan \\ ${ }^{7}$ Science and Research Department, Osh State University, Osh, Kyrgyzstan \\ Email: *jypar.science@oshsu.kg
}

How to cite this paper: Madaminova, D., Zulpukarova, A., Sabiralieva, Z., Abdraeva, A., Zulpukarov, K., Bekkulova, D., Raiymova, G., Osmonbaeva, Z., Ibraimova, S., \& Abdullaeva, Z. (2021). Definition of Concept in the Russian Linguistic Field as a Cognitive Category. Open Journal of Modern Linguistics, 11, 149-157.

https://doi.org/10.4236/ojml.2021.112013

Received: February 16, 2021

Accepted: March 28, 2021

Published: March 31, 2021

Copyright $\odot 2021$ by author(s) and Scientific Research Publishing Inc. This work is licensed under the Creative Commons Attribution International License (CC BY 4.0).

http://creativecommons.org/licenses/by/4.0/

\begin{abstract}
This article discusses main approaches in the study of concept as a category of cognitive linguistics. Concept in the field of the cognitive linguistics can be observed as a unit of memory, also it is complex and multi-faceted phenomena. It has many varieties and types, defined and classified by linguocognitologists in completely different ways. The purpose of this article is to identify and characterize the main parameters of classification and typology of concept adopted in cognitive linguistics. Presentation of the materials carried out using the methods of comparison, analogy, and synthesis. As a result of this research, essential features of the concept were revealed with the greatest degree of completeness, and the most complete definition of the concept was proposed, combining the scientists' contradictory opinions. The relevance of this research is absence of complete definition for concept in cognitive and general linguistics.
\end{abstract}

\section{Keywords}

Concept, Cognitive Linguistics, Culturology, Cognitive Science, Micro Concept, Macro Concept, Mentality

\section{Introduction}

The relevance in this article focused on the contradictory understanding of the 
lingual-cognitive category essence of the concept by scientists, and the absence of a single view on its content, typology, and scope of application. However, explanation of the word concept is missing in the modern explanatory and semantic dictionaries (Prokhorov, 2009). This implies the necessity to formulate a general consistent definition of the word concept in linguistics. The concept was also studied as the main research object of cognitive linguistics (Abdikalyk et al., 2016).

Its use in the scientific, artistic, and colloquially-everyday speech styles was considered (Demyankov, 2001) based on a large texts corpus of various genres; analyzed how this term was used in Latin, French, Italian, and Spanish (on native territory), as well as in German, English, and Russian (on foreign territory) and came into several important conclusions:

1) Languages are varying in time of rooting of the term concept in the humanities, in fiction, and everyday speech. This variation was observed even within the framework of the roman-speaking range, which is the source of this term. In scientific Latin, the word conceptus is rarely used and, most often, in the sense of the type "conceived" rather than "concept". In Italian and Spanish, the word concept (concetto and concepto, respectively) has long been found in fiction texts and was included in a relatively large number of idiomatic combinations, but not in French.

2) In German, the word concept (konzept, koncept, etc.) appears (not in idioms) in the meaning of "sketch", i.e. close to the Russian synopsis. In the English language, the concept as a philosophical term with the meaning of "the concept of a priori" was widely used since the second half of the 19th century. In the Russian language, if we ignore the "citing" mentioned as a term of medieval philosophy, the word concept started to be used frequently from the 1920s, and up to the mid of 1970s, most often as a complete synonym for the term meaning.

The purpose of this study is to form a general cognitive-linguistic definition of the concept from the point of view of the Russian-language linguistic literature. Research was implemented based on the comparison, collation, synthesis and generalization methods.

\section{Understanding the Concept in Russian Language Linguistics}

In the Russian language term concept reaches its peak of usage, when this term is used in another meaning than just a "concept", especially in the humanities. The distinction of concept meaning goes along the line on which people are agreeing with their understanding. People construct concepts to "have a common language" when discussing problems, while concepts are existing by themselves. People reconstruct concepts with varying degrees of confidence. Sometimes referents of the concept and meaning of the term are the same.

In this paper, we have reconstructed the meaning of the term concept, i.e. build up the "concept of the concept" based on observations of its use in different intellectual cultures. Based on this reconstruction, it is proposed to talk 
about the concept of concept and further use of this term in a predetermined meaning, which lies within the framework of international (not only Russian) usage.

In such interpretations, the meaning of the term concept contains an idea of a "rudimentary truth" embodied within Latin conceptus "conceived". The term concept is apparently "conceived", but in reality, we can only be sure of the result of the reconstruction procedure. A peculiar fashion for the term concept in scientific and fiction literature of the late twentieth and the early twenty-first century indicates interest in the reconstruction of those entities in human life that we encounter every day, without thinking about their "true" (a priori) meaning. It turned out that it is far from always possible to "agree" on concepts: it is sometimes more productive to reconstruct habitual meanings or concepts, and, based on established ideas, old concepts, without destroying them, try to construct new concepts. The new, especially in ethics, is a reconstruction of the old. Justification of this situation is facing us both in public and academic life.

"What comes first-an egg or a chicken?" There is an inverse relationship: a set of concepts, images, stereotypes, etc. acquired in the process of understanding the world of reality, associated with the practical realization of being in this reality. Acquisition of the broadcast experience of previous generations, etc. contributes to the formation of the "concept" of this sphere in human existence, which regulates this existence. Due to the uncertainty and vagueness of concept boundaries, there are various interpretations and explanations of it. In modern publications, such generalized analyzes are conducted primarily in two directions: first, on the epistemology of the concept, and second, on the typology of concepts (Abdyvalieva et al., 2017). In the first case, an association based on a common understanding of the origin of the concept and its "location", its relationship with reality, and the forms of its manifestation. Secondly, from the point of view of a specific science taking into account its conceptual apparatus for a given term is necessary.

Typology of concepts as mental formations can be conducted based on their standardization (individual, group, and national). According to the content, they can be divided into representations, images, schemes, concepts, scenarios, frames, etc. In terms of language, concepts can be represented by lexemes, phrase combinations, free phrases, syntactic constructions, and even texts and sets of texts. A concept is a mental unit, an element of consciousness. Human consciousness is the mediator between the real world and language. Cultural information enters the consciousness, then filtered, processed, and systematized. Concepts form a kind of "cultural layer" mediating between a person and the outside world. Concepts are existing in the consciousness (mental world) of a person in the form of "bundles" of concepts, knowledge, associations, and experiences.

\section{Criteria of the Concept Typology}

Classification of concepts can be carried out according to several parameters; however, all these parameters should be assigned equally to all classified ele- 
ments. For example, in our case it is necessary to establish at least several parameters of the phenomenon being described, therefore, it is necessary to classify researchers' views on these parameters. After such classification, it is possible to identify the trunk and peripheral points of view; and the most characteristic features of the object, as well as on this basis, try to formulate an understanding of the object itself. Hereinafter, a review of approaches and concepts is carried out according to the works (Prokhorov, 2009), (Drofa, 2011), (Popova \& Sternin, 2010), (Sabitova, 2013), (Abdyvalieva et al., 2017) and other linguists-cognitivism.

These parameters will include the following answers to questions (Figure 1):

\section{1) What is the concept?}

- Linguistic-cognitive phenomenon;

- Psycholinguistic phenomenon;

- Abstract scientific concept;

- The basic unit of culture;

- Linguacultural phenomenon;

2) What are the concept units are?

- Mentality unit;

- A unit of consciousness/mental structure;

- Unit of the language of thought;

- A unit of linguistic vision of the world (linguistic [naive] picture of the world) and a product of a national-cultural mentality;

- Unit of the mental-lingual complex;

- Unit of information about the world.
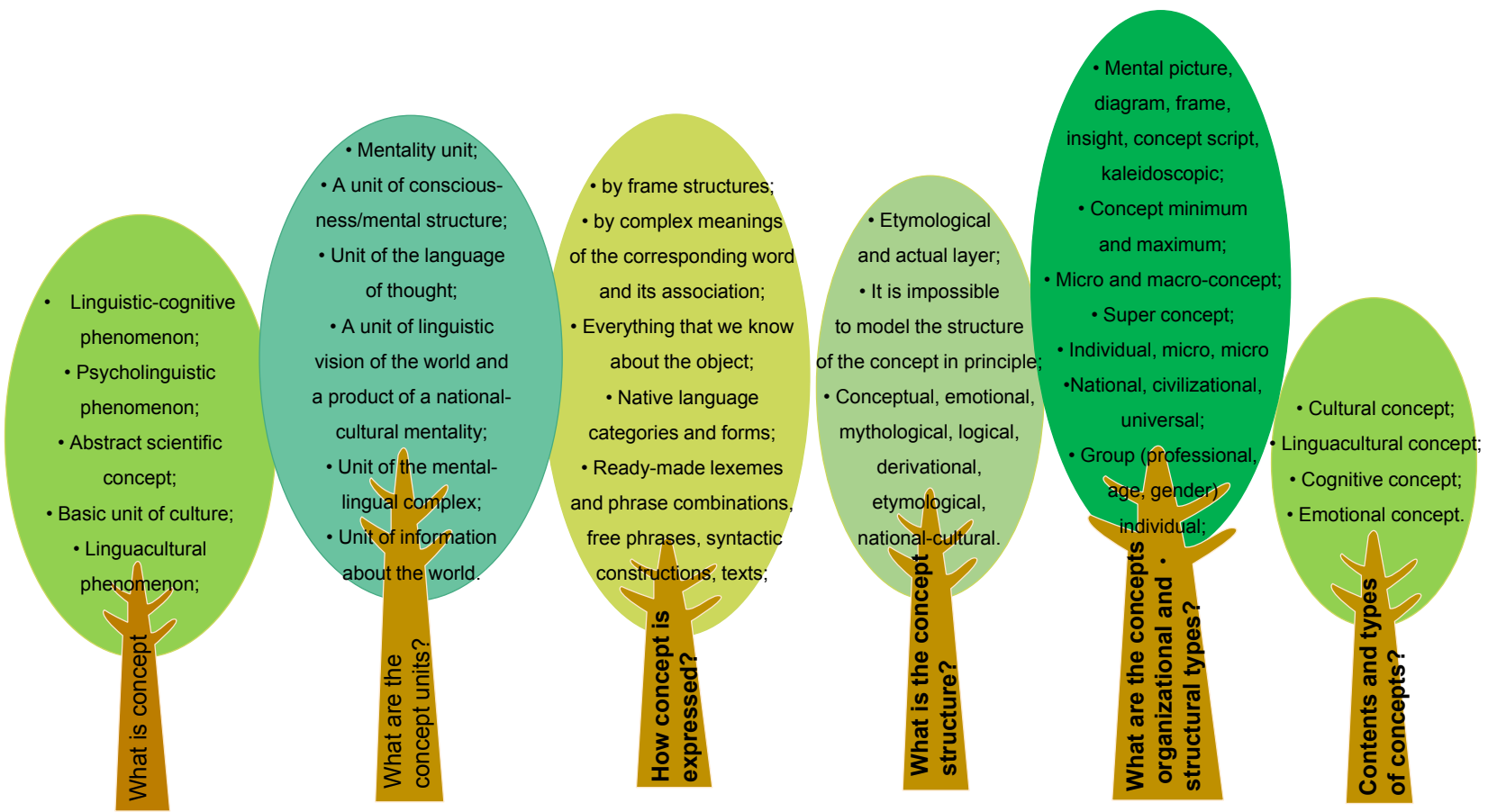

Figure 1. Concept map showing answers to questions about concept. 


\section{3) How is the concept expressed?}

- Gestalt, frame structures;

- A complex of meanings of the corresponding word and its association and connotations;

- Everything that we know about the object;

- Categories and forms of the native language;

- Ready-made lexemes and phrase combinations, free phrases, syntactic constructions, texts, and sets of texts;

- By word;

- The root of the word;

- The whole set of linguistic and non-linguistic means;

4) What is the concept's structure?

- Core and periphery;

- It is impossible to model the structure of the concept in principle;

- Conceptual, emotional-evaluative, mythological, logical, derivational, etymological, national-cultural, and other layers.

5) What are the concepts of organizational and structural types?

- Mental picture, concept diagram, concept frame, concept insight, concept script, kaleidoscopic;

- Concept minimum and concept maximum;

- Micro and macro-concept;

- Super concept;

- The individual, micro group, macro group, national, civilizational, universal;

- Group (professional, age, gender) and individual;

- Ethnocultural and socio-cultural;

- Names, unique and universal; archetypal and invariant types;

6) What are the contents types of concepts?

- Cultural concept;

- Linguacultural concept;

- Cognitive concept;

- Emotional concept.

From the presented classification of content-structural elements, it is easy to conclude that the understanding of the "concept" by various authors of only the last thirty years is practically not reducible to any unity. Moreover, the distribution of the views of researchers on the concept proposed above may seem non-controversial, since it is not always possible to determine precisely the definitions or descriptions of this phenomenon. Therefore, many authors appeared in the list of approaches in several explanations.

\section{Study Approaches of the Concept in Linguistics}

The second classification, which is present in modern works, is the classification of the term "concept" in terms of its reference to a particular scientific discipline. This classification is presented in several studies-in our opinion; this is most 
fully done in the works (Abdulatov, 2006), (Madaminova \& Abduvalieva, 2017), (Zulpukarov et al., 2011), (Zulpukarov, 2017) and other researchers.

We now turn to the specific definitions of the concept, presented in several recent works, in which, in our opinion, this phenomenon is most thoroughly and comprehensively considered.

\subsection{Concept as a Linguistic-Cognitive Phenomenon}

A concept is a term that serves to explain the units of mental resources of our consciousness and the information structure that reflects human knowledge and experience; an operational content unit of memory, mental lexicon, conceptual system and language of the brain, the whole picture of the world, reflected in the human psychology. Concept corresponds to the idea of the meanings in which a person operates in the process of thinking, and which reflects the content of experience and knowledge. The content of all human activity results in the processes of knowledge of the world in the form of certain "quanta" of knowledge (Kubryakova, 1994; Kubryakova et al., 1997). Concept is understood as a global thinking unit, which is a quantum of structured knowledge. Apparent conceptual irregularities and asymmetries which Turner and Fauconnier observe in their emergence are alternatively explained as contextual implications motivated by and derived from the convergence of information (Mendoza Ibáñez, 1998).

Concepts can be categorized as ideal entities that are formed in the human mind:

1) from his immediate sensory experience with the perception of reality by the senses; 2) from direct operations of a person with objects, from his subject activity; 3) from the mental operations of a person with other concepts already existing in his consciousness-such operations may lead to the emergence of new concepts; 4) from language communication (the concept can be communicated, explained to the person in a language form, for example, in the learning process, in the educational process); 5) From independent knowledge of the meanings of linguistic units (ex: the child asks what democracy is, an adult looks at the meaning of an unknown word in the dictionary and through it gets acquainted with the corresponding concept). "The national concept is the most general, as abstract as possible, but specifically representative of (linguistic) consciousness, subjected to cognitive processing the idea of "the subject in the aggregate of all valence bonds marked by national cultural marks” (Krasnykh, 2016).

\subsection{Concept as a Psycholinguistic Phenomenon}

In this understanding, the concept acts as a perceptual-affective dynamic formation in the cognitive and communicative activity of an individual that obeys the laws of a person's mental life and, as a result, differs from concepts and meanings as products of scientific description from the standpoint of linguistic theory (Zalevskaya, 2001). A concept is a block of knowledge representing a set of concrete-shaped (visual, auditory, taste, tactile, olfactory), conceptual (including 
value), prototypical, gestalt, frame, script, and other elements in human psychology.

\subsection{Concept as a Linguistic and Cultural Phenomenon}

From this point of view, the concept was defined as a unit designed to tie together scientific research in the field of culture, consciousness, and language, since it belongs to consciousness, is determined by culture, and objectified in language. Cultural entities in their inner diversity demonstrate that the concept of the contemporary world cannot be understood outside the analysis of cultures as identity structures (Doina et al., 2011). Concept formation is a process of reducing the results of experiential cognition of reality to the limits of human memory and relating them to previously learned cultural-value dominants (Bidzan-Bluma \& Lipowska, 2018). The linguacultural concept is a bunch of ethno culturally marked meaning, necessarily has its name, which usually coincides with the dominant of a certain synonymous series or with the core of a certain lexico-semantic field. People's understanding of abstract concepts can include knowledge gained from language describing situations and events for which those concepts are relevant, such as sensory and motor information (McRae et al., 2018).

\subsection{Concept as a Gnoseological and Pedagogical Phenomena}

Such an understanding is characteristic of scholars and educators who work directly with students. It is believed that the awareness of semantic-cognitive unity of words, phrases, and sentences contributes to the integrated understanding, memorization, and use of linguistic units in their paradigmatic-thematic unity and serves as an aid for accelerated learning the language as a non-native. Further citing definitions and models of understanding the concept does not have, in our opinion, meaningful meaning, since they serve only as transformations of the above-mentioned ones. They reflect all those main components, which in their certain combination will determine the understanding of the term "concept".

Based on the above, we can conclude that the main features of the concept are:

1) Belonging to the sphere of consciousness as an element of memory and thinking; 2) Discreteness, relative autonomy of education, existence and functioning; independence from the language and its type; 3) Correlation with the displayed objects and phenomena of the surrounding world; 4) Complexity, bulk, multidimensionality and multi-layer structure; 5) The ability to serve as the basis of the cognitive code of a person and society, which ensures communication and mutual understanding of people with its identity; 6) The ability to materialize in linguistic signs; the complexity of verbal and non-verbal signs; 7) Combination of manifestation in the linguistic signs of its lexicographical, semantic, derivational, etymological, socio-cultural (religious, mythological, civilizational, etc.), symbolic and other layers and aspects; 8) Variability, transfor- 
mability, flexibility to changing environments 9) Passivity in the memory of a person outside the situations and events that actualize him; 10) Conditionality, blurring of boundaries, the presence of the core and periphery, intermediate, boundary and other "quanta".

Generally, the modern understanding of the "concept" phenomenon in the main lingual-cognitive aspect was studied. The concept is a main category in linguistic anthropocentrism, and used as the initial basis for research on linguistic and cognitive, linguistic, cultural, linguistic, conceptual, mentalist, and other branches of modern linguistics

\section{Conclusion}

As a result of our comparative analysis on the essence of the term concept, we can offer its most general definition, reflecting all essential properties. We call the concept a discrete, three-dimensional, and multi-layered unit of memory and thinking, which occurs in the process of human cognitive activity, in a group of people and the whole society. It forms the basis of people's thought-speech code, ensuring their mutual understanding, carries complex-encyclopedic information about the reflected object and phenomenon. Concept acts as an element of the cognitive-linguistic picture of the world of the ethnos and is implemented by various linguistic and extra-linguistic means. It materializes mainly in the language, objectifying in words, phrases, idioms, proverbial and proverbial sayings, etc. The definition we propose is general reflects all the main features of the concept; therefore, it can be useful in describing its various types and varieties.

Social significance in this study is introduction with the achievements of cognitive linguistics and linguo-conceptology in the post-Soviet linguo-ethnocultural field. Practical implication is determined by using research results in courses "Introduction to Linguistics", "General Linguistics" and "Cognitive Linguistics" at philological faculties of universities.

\section{Conflicts of Interest}

The authors declare no conflicts of interest regarding the publication of this paper.

\section{References}

Abdikalyk, S. K., Abitzhanova, Z. A., Otarbekova, Z. K., Kaidarova, G. K., \& Seidullayeva, G. A. (2016). Concept as the Main Research Object of Cognitive Linguistics. International Journal of Environmental and Science Education, 11, 3167-3178.

Abdulatov, A. A. (2006). Description of Paremias for Educational Purposes (149 p.). Bishkek: Kyrgyz Russian Slavic University.

Abduvaliyeva, E. A., Madaminova, D. P., \& Zulpukarov, A. K. (2017). Concept as a Category of Epistemology and Linguistics. Modern Trends in the Development of Science and Technology, Belgorod, 3, 12-15.

Bidzan-Bluma, I., \& Lipowska, M. (2018). Physical Activity and Cognitive Functioning of Children: A Systematic Review. International Journal of Environmental Research and 
Public Health, 15, 800. https://doi.org/10.3390/ijerph15040800

Demyankov, V. Z. (2001). Concept and Concept in Fiction and Scientific Language. Questions of Philology, 1, 35-46.

Doina, D., Calin, F., Elena-Adriana, T., \& Anisoara, P. (2011). The Concept of Cultural and Traditional Archetype. Procedia-Social and Behavioral Sciences, 15, 1493-1496. https://doi.org/10.1016/j.sbspro.2011.03.317

Drofa, L. I. (2011). Key Concepts of Cognitive Linguistics (pp. 36-44). Osh.

Krasnykh, V. V. (2016). Vocabulary and Grammar: Fundamentals of Psycholinguistics (496 p.). Moscow: L Gnosis.

Kubryakova, E. S. (1994). The Initial Stages of the Formation of Cognitivism: Linguistics, Psychology Cognitive Science. Questions of Linguistics, 4, 34-47.

Kubryakova, E. S., Demyankov, V. Z., Pankrats, Y. G., \& Lizina, L. G. (1997). A Brief Dictionary of Cognitive Terms (281 p.). Moscow: Moscow University.

Madaminova, D. B., \& Abduvalieva, E. A. (2017). On the Conceptual and Evaluative Content of the Concept "Custom/Salt" in Russian and Kyrgyz Languages. Belgorod, 3, 94-97.

McRae, K., Nedjadrasul, D., Pau, R., Lo, B. P., \& King, L. (2018). Abstract Concepts and Pictures of Real World Situations Activate One Another. Topics in Cognitive Science, 10, 518-532. https://doi.org/10.1111/tops.12328

Mendoza Ibáñez, F. J. R. (1998). On the Nature of Blending as a Cognitive Phenomenon. Journal of Pragmatics, 30, 259-274. https://doi.org/10.1016/S0378-2166(98)00006-X

Popova, Z. D., \& Sternin, I. A. (2010). Cognitive Linguistics (314 p.). Moscow: AST East-West.

Prokhorov, Y. E. (2009). In Search of a Concept (2nd ed., 176 p.). Moscow: Nauka.

Sabitova, Z. K. (2013). Linguoculturology (528 p.). Moscow: Flinta.

Zalevskaya, A. A. (2001). Psycholinguistic Approach to the Problem of Concept. In $\mathrm{Me}$ thodological Problems of Cognitive Linguistics (pp. 37-41). Voronezh: VGU.

Zulpukarov, K. Z. (2017). The Semantic Structure of the Kyrgyz Phrases and Sentences from the Point of View of the Chinese Language (pp. 793-805). Moscow: Flinta.

Zulpukarov, K. Z., Drofa, L. I., \& Kalmurzaeva, A. A. (2011). Concept of God in Religious Discourse. In Osh State University Bulletin (pp. 3-8). Osh: Osh State University. 